\title{
Fault Injection for Semi-Parametric Reliability Models ${ }^{12}$
}

\author{
Allan L. White \\ MS 130 \\ NASA Langley \\ Hampton, Virginia 23681 \\ 757-864-6199 \\ a.1.white@larc.nasa.gov
}

\begin{abstract}
A new result about the reliability models of reconfigurable digital systems is derived and then applied to the problem of establishing ultra reliability by fault injection experiments. The result shows that the complicated fault recovery procedure can be adequately described by a few parameters. The resulting reduction in modeling and experimental effort brings establishing extremely low probabilities of failure within experimental reach. There is a discussion of the differences between this approach and previous efforts. The result is used to design experiments for several example systems.
\end{abstract}

\section{TABLE OF CONTENTS}

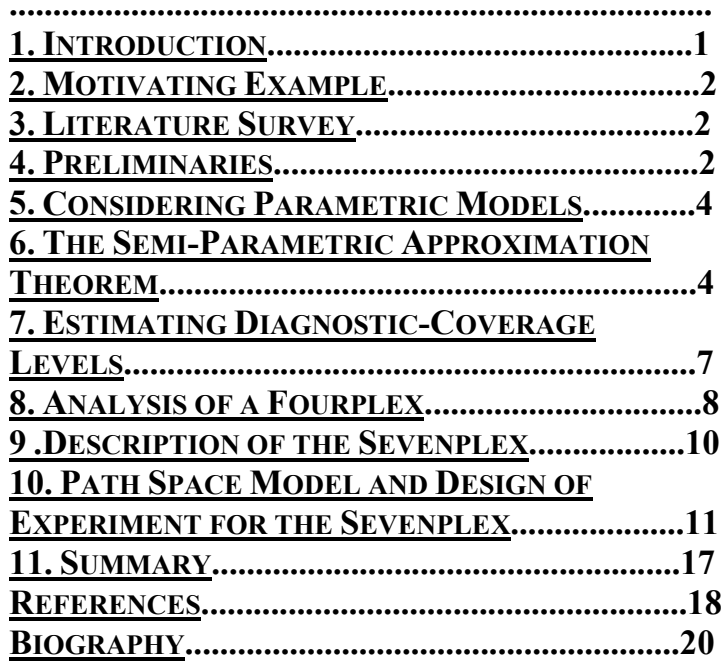

\section{INTRODUCTION}

A long standing problem in the field of ultra-reliable digital control systems is the design of a fault injection experiment for system validation. Such an experiment combines arguments-from-design, field-data-on-faultoccurrence, and results-from-fault-injections. If the system successfully completes the experiment, then the system has a given reliability at a certain confidence level.
The next several sections describe a type of validation experiment based on four factors. (1) If there is a design argument that the system operates acceptably when it is fault free then the experiment need only establish system fault recovery. (2) If system recovery is fast (a desirable property) then fault injection need last only a short period of time. (3) If the system uses quality components then the probability of a component failure is small. (4) If there is a simple but adequate description of system fault recovery then only a few parameters need be estimated.

The procedure below is a two step process. The fault injection experiments verify the model. The model is used to calculate system reliability. More accurately, the experiments verify that a model is conservative, and this model is used to place an upper bound on the probability of system failure. In particular, there is no claim of model uniqueness.

There has been a considerable amount of effort in fault injection, but to the best of the author's knowledge no scheme has been proposed to establish ultra reliability by experiment. Section two presents a typical impossibility argument. Section three summarizes a literature search. Since this approach is different from previous efforts, section four details some of the differences and their motivation. The biggest difference is that this approach does not follow the historical progression of more and more complicated models. The reasons for the divergence are given in section five. The heart of this approach is a new result that says system fault recovery can be adequately described by the first two moments of the recovery distribution. This eliminates the need to construct and verify complex models. It also reduces the experimental effort to recording a single observable parameter. The theorem is in section six. Section seven contains the material for examining the diagnosticcoverage level. An elementary application of the results to a fourplex is in section eight. An extensive application to a sevenplex is in section nine.

\footnotetext{
${ }^{1}$ U.S. Government work not protected by U.S. copyright

${ }^{2}$ IEEEAC Paper \#1033, Version 2
} 


\section{Motivating EXAMPLE}

To motivate the results and the emphasis on reducing the level of effort, consider the following argument.

A proposed requirement for an electronic flight control system is that the chance of system failure be less than one in a billion for a ten-hour flight. To establish this at the $100(1-1 e-9) \%$ confidence level requires $21,000,000,000$ ten hour flights without failure. A fleet of 1000 planes flying continuous ten-hour missions would require 24,000 years. Not even a six order magnitude gain in efficiency could make this experiment feasible.

The reply is that the argument above treats the system as an unknown black box. In reality, we know as lot about the system (because we built it). First we know the structure, which permits using arguments-from-design and tests. (One option is to concoct the arguments-fromdesign and then construct the system.) Second we know the failure rate of the components, which permits conducting quantitative fault injection experiments. The goal below is to use this structural and stochastic knowledge to bring establishing ultra-reliability within reach.

\section{LITERATURE SURVEY}

There is a large body of literature on fault injection, and this section can only offer a cursory description of the efforts. Nevertheless, it is possible to describe what has been done, and then note how this paper differs from previous work. The survey below is by topic. Since most papers discuss several topics, most papers appear more than once.

There are papers that survey the field and/or advocate fault injection as a useful tool $[9,14,50,51,53]$. One question is authenticity--do laboratory fault injections mimic actual fault occurrences [22, 45, 55]. Some papers use system architecture to design efficient and effective fault injection $[1,4,6,8,20,21,24,25,26,27,29,30$, $31,39,40,42,44,46,47,48,49,55]$. Others use the results of fault injections to compare or design systems [4, $8,11,12,23$ 30, 36, 38, 39, 41, 47, 54]. Fault injections are used to search for design flaws $[3,6,17,48]$. They are used to test software as well as hardware $[8,13,28$, $50,51,52,53]$. There are a number of programs and tools for efficient fault injection $[2,7,10,22,24,26,28,31$, $35,43,45,49,55,56]$. There are efforts to model fault propagation and effect $[5,7,12,17,19,22,23,27,28,30$, $32,36,38,39,40,41,44,45,47,50,52]$. Coverage is a popular topic, and the meaning of coverage can vary from simple detection to complete system recovery and reconfiguration $[1,2,3,4,5,10,11,12,15,16,17,18$, $20,21,27,29,31,33,36,37,38,39,40,41,42,43,44$, $54,55]$. There is efficient estimation of coverage $[15,16$, $18,27,36,43]$. There is incorporating coverage into a reliability model (and there are additional comments on this in section seven) $[5,13,47]$.

This paper is a modest effort, but different from all the above. It considers only hardware. The goal is to derive results in probability that permit establishing ultra reliability (for hardware) with a moderate fault injection effort. This paper is enough different from previous efforts that it does not use any of the above references. The work below is technically self contained with two possible exceptions. (1) Some of the requirements are motivated by the results in [57] as described in the subsection on diagnostic-coverage below. Experiments based on this approach may or may not use fault injection techniques that previously have been developed.

\section{Preliminaries}

\section{Confidence Level}

A confidence level is a quantitative measure of the quality of an experiment. If there are random elements present, it is possible for an experiment to mislead us. For instance, an unfair coin when flipped twenty times could return ten heads and ten tails and be declared fair. The confidence level gives the probability that the experiment has misled us. A $99 \%$ confidence level means that there is a 0.01 (or less) chance that we have been misled. This paper takes the position that the quality of the experiment should match the importance and quality of what is being established. In the following if the requirement is that the probability of system failure be $\mathrm{p}$ (or less), then the experiment is designed to have a confidence level of $100(1-\mathrm{p}) \%$.

Since a reliability model has numerous parameters to be estimated, the final confidence level is a combination of the confidence level for each of the parameters. The result used is as follows [58].

Suppose $\left[\alpha_{\mathrm{i}}, \beta_{\mathrm{i}}\right]$ is a $100\left(1-\mathrm{h}_{\mathrm{i}}\right) \%$ confidence interval for $\mathrm{p}_{\mathrm{i}}$ for $1 \leq \mathrm{i} \leq \mathrm{n}$, then $\left(\left[\alpha_{1}, \beta_{1}\right], \ldots,\left[\alpha_{\mathrm{n}}, \beta_{\mathrm{n}}\right]\right)$ is a $100\left(1-h_{1}-\ldots-h_{n}\right) \%$ confidence interval for $\left(\mathrm{p}_{1}, \ldots, \mathrm{p}_{\mathrm{n}}\right)$.

\section{Field Data}

One of the difficult areas in the fault tolerant approach to reliability is gathering field data on the occurrence and behavior of faults. This section considers several possibilities and how they relate to fault injection and system design.

An idealized scenario is that the components are bench tested under the proper environmental conditions until errors are observed on the output pins. The failure rate is estimated and used in the probability arguments (as illustrated in section eight). The system is designed to 
detect failures that appear at the output pins of the devices. In the experiments, faults are injected at the output pins. The actual fault pattern that appears at the output pins of a faulty device may be hard to obtain. Hence, part of system design may be some arrangement for the detection of any fault pattern.

It has been suggested that faults are characterized by open or short conditions at the input pins. If this characterization of faults is accepted, then the system must be designed to detect this type of fault, and the experiments must inject this type of fault.

It is apparent that a system will be designed and validated for a given class of faults. This class of faults will have to be stated (and agreed upon) in the initial stages of design.

\section{Terminology}

The approach and hence the terminology in this paper are different from other approaches, in particular from the terminology in [60].

In this paper, a fault is a device input-output malfunction. As described above, it is assumed the distributions for the appearance of the malfunctions are known, and it is assumed that the lab can mimic these malfunctions. The reproduction of a malfunction in the lab is known as a fault injection. Section six determines what must be observed during a fault injection in order to construct a conservative reliability model.

The assumption in this paper is that the system is a collection of redundant units that detect and guard against faults by majority voting. For detection, the effects of the fault (errors) must propagate to the output registers of the redundant unit. System recovery depends on the system. It will be assumed, for continued reliability, that system recovery includes the detection of the fault in order that the faulty unit can be replaced during maintenance. System recovery may include configuring the faulty unit out of the working group and replacing it with a spare (if a spare is available). For practicality, it is likely that during the experiment a maximum time will be allotted for system recovery which includes the propagation of the errors to the output registers plus whatever additional action is required. As described below, failure of the system to recover during this period will be considered a system failure. During system recovery, performance must remain within specifications or it is considered a system failure.

If a fault fails to propagate errors to the output register, this can be a cause for system redesign. The reasoning is that if one input-output malfunction of a device does not propagate, then other input-output malfunctions of this device may not propagate. In addition, as mentioned in the previous subsection on field data, the actual fault pattern that appears at the output pins of a faulty device may be hard to obtain and part of system design may be some arrangement for the detection of any fault pattern.

The terminology above is close to the terms commonly used [60]. There are four major points of comparison. First, in [60] dependability is used instead of ultra reliable. Second, in [60], dependability (or ultra reliability) is the quality of delivered service as perceived by another system. There is system failure if the delivered service deviates from the specified service. This definition of system failure is equivalent to the approach in this paper if multiple systems are used where one system consists of lab monitoring that observes two items: (1) the system has detected the fault and taken appropriate action and (2) the system under observation continues to adequately perform its intended function while recovering from the fault. Under these circumstances, for both this paper and [60] a system failure occurs when the delivered service deviates from the specified service. Third, in [60], a fault is an internal failure of a device and an input-output malfunction is considered an error. This paper considers an input-output malfunction to be the fault since an internal failure of a device is usually not observable. Since the input-output malfunction is observable, it is the event that is recorded to obtain the failure rate of the devices. This relates field data and fault injection experiments.

Fourth, in [60], "faults, errors, and failures are all undesirable circumstances." In contrast, in this paper, a fault not propagating errors to an appropriate level within a short period of time is considered a system failure. For the examples in this paper, the appropriate level for error propagation is to the output registers of a unit in a majority voting group. In this case the presence of a fault can be detected, but if the majority vote is not overwhelmed by too many faulty units and if the fault handling procedure (if any) does not cause deviation from the specified service then the system can be considered to have a successful recovery.

This stringent requirement for error propagation is necessary to achieve a high level of diagnostic-coverage, which is discussed in the next subsection.

\section{Diagnostic-Coverage Level}

Coverage can be defined as the (conditional) probability of a good outcome given some fault occurrence. Clearly it is ubiquitous and has a variety of meanings depending on the circumstances.

The approach in this paper is based on the long term effects of lack of diagnostics (coverage) studied in [57]. In [57] systems are subject to periodic maintenance which replaces units detected as faulty while undetected faults accumulate. A unit with an undetected fault is replaced if it acquires a detectable fault. The conditional probability of failure during the next operating period is computed 
given the system has survived the previous operating periods. This conditional probability (system unreliability) approaches a steady state value. There is a precipitous drop in reliability during a system's lifetime given a small lack of diagnostics.

\section{System Design Requirements}

The experiments described below make extremely high demands on system design. It is unlikely that a system designed without considering these demands can be verified to have ultra reliability. It is not known if any existing system has the necessary properties. In fact, it is not known if it is possible to design and build a system with the necessary properties. What, then, is the purpose of designing these experiments?

The first comment is that while the requirements are high, and possibly not yet achieved, they are common design goals. They are not considered impossible.

The second comment is that the requirements delineated below are not as high as other proposed requirements. In the absence of quantitative methods, the option is to prove perfection.

Finally, the experiments determine what is necessary from the areas of field data, system design, tests, and arguments-from-design. They are an integrating factor for all the elements.

\section{Central limit theorem}

It will be shown in section six that an upper bound on the probability can be computed by using just the averages of the system recoveries. Of course, confidence intervals for averages are derived from the central limit theorem that says a sample average is approximately normally distributed. The problem below is that the confidence levels are extremely high, and the normal approximation may or may not be accurate enough. This statistical point requires more study.

\section{Considering Parametric Models}

This section considers some of the apparent problems with using a parametric (specified distribution) model to describe fault/error behavior and system recovery.

The first question is which model to use. Two simple examples are in figure 1. Figure 1(a) displays a single step model with a constant rate distribution. Figure 1(b) displays a three step (detection, identification, and reconfiguration) model with constant rate distributions. $\delta$

(a)

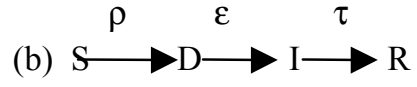

Figure 1 - Two fault recovery models

Numerous other models have been proposed, with an historical increase in complexity. None of these models have been shown to be adequate at the ultra high level (less than one in a billion chance of failure).

The more complicated models have a number of parameters to estimate with some of them difficult to observe such as the interaction between a hardware fault and the application software.

In addition, most models are Markov models where the individual transitions are continuous and memoryless. This does not fit a digital system with its discrete time steps, periodic operation, and fixed time procedures.

For emphasis, these apparent problems may not be real problems. It is conceivable that establishing a parametric model is straightforward. Nevertheless, with the above in mind, the next section offers a different approach.

\section{The SEMI-PARAMETRIC APPROXIMATION THEOREM}

An open problem in the modeling of ultra reliable systems is choosing the fault-error-handling-model that describes fault behavior, error propagation, and the system response to errors. Since the quantities to be computed are extremely small and the systems are safety critical, no detail can arbitrarily be ignored. On the other hand, complex models pose burdens in computation, parameter estimation, and hypothesis testing (is the model correct?). The theorem below shows that an upper bound for the probability of failure can be obtained by just the first moments of system recoveries. It is desirable that system recoveries be fast. If system recoveries are fast (small first and second moments) then the theorem shows that this upper bound is a tight bound.

Subsequent sections in the paper use the upper bound. The presence of a tight lower bound demonstrates that this is reasonable.

A reliability model can be regarded as a collection of paths from the initial state (or states) to the failure state (or states). By the semi-Markov property, an arbitrary path can be arranged as in figure 2 . 
In the first line of figure 2 the successful transitions are constant rate processes competing against other constant rate processes. In the second line the successful transitions are general distributions (system recovery distributions) competing against other general distributions and constant rate processes. In the third line the successful transitions are constant processes competing against general distribution functions and other constant rate processes. For notation

$\mathrm{D}(\mathrm{T})=$ Probability of traversing the path in figure 2 by time T

$\mathrm{W}(\mathrm{T})=$ Probability of reaching state $\mathrm{B}_{1}$ by time $\mathrm{T}$ $\mathrm{p}\left(\mathrm{F}_{\mathrm{i}}\right)=$ Probability the transition $\mathrm{dF}_{1, \mathrm{i}}$ is successful $\mu\left(F_{i}\right)=$ First conditional moment of $\mathrm{dF}_{1, \mathrm{i}}$

$\sigma^{2}\left(F_{i}\right)=$ Conditional variance of $\mathrm{dF}_{1, \mathrm{i}}$

$\mu\left(C_{j}\right)=$ First moment of the holding time in state $C_{j}$

$\sigma^{2}\left(C_{j}\right)=$ Second moment of the holding time in $C_{j}$

The probability $\mathrm{W}(\mathrm{T})$ is easy to compute. A convenient approximation is

$\frac{\lambda_{1} \cdots \lambda_{\mathrm{k}}}{\mathrm{k} !} \geq \mathrm{W}(\mathrm{T}) \geq \frac{\lambda_{1} \cdots \lambda_{\mathrm{k}}}{\mathrm{k} !}\left[1-\frac{\mathrm{T} \sum_{\mathrm{i}=1}^{\mathrm{k}}\left(\lambda_{\mathrm{i}}+\gamma_{\mathrm{i}}\right)}{\mathrm{k}+1}\right]$

Let

$$
\begin{aligned}
\Delta= & {\left[\mu\left(\mathrm{F}_{1}\right)\right]^{1 / 2}+\ldots+\left[\mu\left(\mathrm{F}_{\mathrm{m}}\right)\right]^{1 / 2} } \\
& +\left[\mu\left(\mathrm{C}_{1}\right)\right]^{1 / 2}+\ldots+\left[\mu\left(\mathrm{C}_{\mathrm{n}}\right)\right]^{1 / 2}
\end{aligned}
$$

Assume

$$
\mu\left(F_{1}\right), \ldots, \mu\left(F_{m}\right), \ldots, \mu\left(C_{1}\right), \ldots, \mu\left(C_{n}\right)<1
$$

and $\Delta<1$.
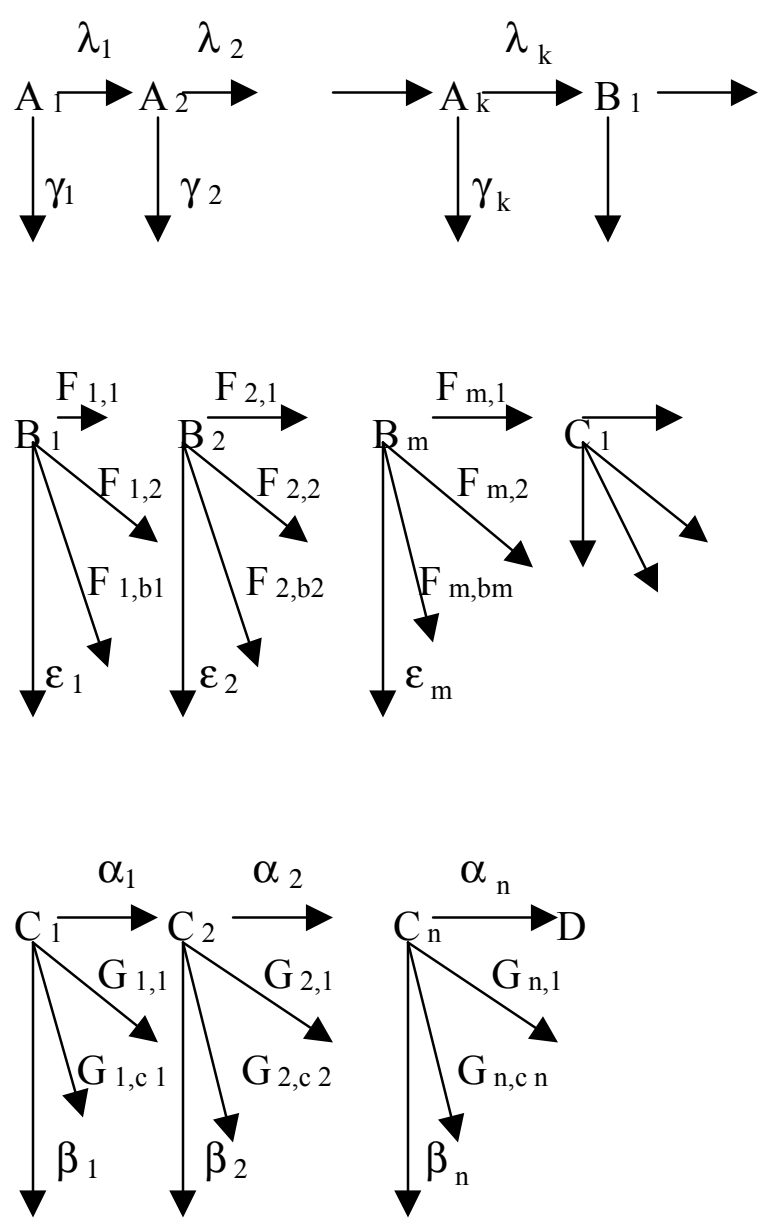

Figure 2 - Arbitrary Path in a Semi-Markov Model

Theorem: With the assumptions and notation as above

$$
\begin{aligned}
& \text { W(T) } \prod_{i=1}^{m} p\left(F_{i}\right) \prod_{j=1}^{n} \alpha_{j} \mu\left(C_{j}\right) \\
& \geq D(T) \\
& \geq W(T-\Delta) \prod_{i=1}^{m} p\left(F_{i}\right)\left[1-\frac{\mu^{2}\left(F_{i}\right)+\sigma^{2}\left(F_{i}\right)}{\mu\left(F_{i}\right)}\right] \\
& \quad \prod_{j=1}^{n} \alpha_{j} \mu\left(C_{j}\right)\left[1-\frac{\mu^{2}\left(C_{j}\right)+\sigma^{2}\left(C_{j}\right)}{\mu\left(C_{j}\right)^{3 / 2}}\right]
\end{aligned}
$$

The proof uses three standard results in probability. If $\mathrm{H}$ is a distribution such that $\mathrm{H}(0-)=0$, then 


$$
\begin{aligned}
& \int_{0}^{\infty}[1-H(t)] d t=\int_{0}^{\infty} \mathrm{t} d H(t)=\mu(H) \\
& 2 \int_{0}^{\infty} t[1-H(t)] d t=\int_{0}^{\infty} t^{2} d H(t)=\mu^{2}(H)+\sigma^{2}(H) \\
& \int_{c}^{\infty} d H(t) \leq \frac{\mu^{2}(H)+\sigma^{2}(H)}{2} \quad \text { for } c>0
\end{aligned}
$$

For illustrative purposes, the first assertion will be proved. Assertion (5) is true in the sense that if one integral is finite then the other is finite and the two are equal. The integrals can be considered either Riemann-Stieltjes or Lebesgue-Stieltjes [61]. In either case the integrals can be approximated (arbitrarily closely) by step functions [61]. Choose a partition of the interval $[0, \mathrm{~T}]$

$$
0=\mathrm{t}_{0}<\mathrm{t}_{1}<\ldots<\mathrm{t}_{\mathrm{n}}=\mathrm{T} .
$$

The lower sum for $\int_{0}^{\mathrm{T}}[1-\mathrm{H}(\mathrm{t})] \mathrm{dt}$ minus the lower sum for $\int_{0}^{\mathrm{T}} \mathrm{tdH}(\mathrm{t})$ is

$$
\sum_{k=1}^{n}\left[1-H\left(t_{k}\right)\right]\left(t_{k}-t_{k-1}\right)
$$$$
-\sum_{\mathrm{k}=1}^{\mathrm{n}} \mathrm{t}_{\mathrm{k}-1}\left[\mathrm{H}\left(\mathrm{t}_{\mathrm{k}}\right)-\mathrm{H}\left(\mathrm{t}_{\mathrm{k}-1}\right)\right]
$$$$
=\sum_{k=1}^{n}\left(t_{k}-t_{k-1}\right)-\sum_{k=1}^{n} t_{k} H\left(t_{k}\right)+\sum_{k=1}^{n} t_{k-1} H\left(t_{k}\right)
$$$$
-\sum_{\mathrm{k}=1}^{\mathrm{n}} \mathrm{t}_{\mathrm{k}-1} \mathrm{H}\left(\mathrm{t}_{\mathrm{k}}\right)+\sum_{\mathrm{k}=1}^{\mathrm{n}} \mathrm{t}_{\mathrm{k}-1} \mathrm{H}\left(\mathrm{t}_{\mathrm{k}-1}\right)
$$$$
=\mathrm{T}-\sum_{\mathrm{k}=1}^{\mathrm{n}} \mathrm{t}_{\mathrm{k}} \mathrm{H}\left(\mathrm{t}_{\mathrm{k}}\right)+\sum_{\mathrm{k}=0}^{\mathrm{n}-1} \mathrm{t}_{\mathrm{k}} \mathrm{H}\left(\mathrm{t}_{\mathrm{k}}\right)=\mathrm{T}-\mathrm{TH}(\mathrm{T})
$$

This gives

$$
\begin{aligned}
& \int_{0}^{\mathrm{T}} \mathrm{tdH}(\mathrm{t}) \leq \int_{0}^{\mathrm{T}}[1-\mathrm{H}(\mathrm{t})] \mathrm{dt} \\
& \quad \int_{0}^{\mathrm{T}} \mathrm{tdH}(\mathrm{t})+\mathrm{T}[1-\mathrm{H}(\mathrm{T})]
\end{aligned}
$$

Hence, if $\int_{0}^{\infty}[1-\mathrm{H}(\mathrm{t})] \mathrm{dt}$ is finite then $\int_{0}^{\infty} \mathrm{tdH}(\mathrm{t})$ is finite.

Suppose $\int_{0}^{\infty} \mathrm{tdH}(\mathrm{t})$ is finite. Then for any $\varepsilon>0$ there is an $\mathrm{S}$ such that $\mathrm{T}>\mathrm{S}$ implies

$$
\varepsilon>\int_{\mathrm{T}}^{\infty} \mathrm{tdH}(\mathrm{t}) \geq \int_{\mathrm{T}}^{\infty} \mathrm{TdH}(\mathrm{t})=\mathrm{T}[1-\mathrm{H}(\mathrm{T})]
$$

Hence, for the integrals in (5), if either is finite then both are finite and the two are equal.

Proof of the theorem

Let $q(t)$ be the density function for the probability of reaching state $B_{1}$ of figure 2 .

$$
\begin{aligned}
& D(T)=\int_{0}^{T} \\
& \int_{0}^{T-t} \cdots \int_{0}^{T-t-x_{1}-\cdots x_{m-1}} \\
& \int_{0}^{T-t-x_{1} \cdots x_{m}} \cdots \int_{0}^{T-t-x_{1} \cdots x_{m}-y_{1} \cdots y_{n-1}} \\
& q(t) \\
& e^{-\varepsilon_{1} x_{1}}\left[1-F_{1,2}\left(x_{1}\right)\right] \cdots\left[1-F_{1, b_{1}}\left(x_{1}\right)\right] \\
& \quad \vdots \\
& e^{-\varepsilon_{m} x_{m}}\left[1-F_{m, 2}\left(x_{1}\right)\right] \cdots\left[1-F_{m}, b_{m}\left(x_{1}\right)\right] \\
& \alpha_{1} e^{-\alpha_{1} y_{1}} e^{-\beta_{1} y_{1}}\left[1-G_{1,1}\left(y_{1}\right)\right] \cdots\left[1-G_{1, c_{1}}\left(y_{1}\right)\right] \\
& \quad \vdots \\
& \alpha_{n} e^{-\alpha_{n} y_{n}} e^{-\beta_{n} y_{n}}\left[1-G_{n, 1}\left(y_{n}\right)\right] \cdots\left[1-G_{n, c_{n}}\left(y_{n}\right)\right] \\
& d y_{n} \cdots d_{1} d F_{m, 1}\left(x_{m}\right) \cdots F_{1,1}\left(x_{1}\right) d t
\end{aligned}
$$

Working with just the limits of integration

$$
\begin{array}{r}
\int_{0}^{\mathrm{T}-\Delta \int_{0}^{\mathrm{r}_{1}} \cdots \int_{0}^{\mathrm{r}_{\mathrm{m}}} \int_{0}^{\mathrm{s}_{1}} \cdots \int_{0}^{\mathrm{s}_{\mathrm{n}}} \leq \mathrm{D}(\mathrm{T})} \\
\leq \int_{0}^{\mathrm{T}} \int_{0}^{\infty} \cdots \int_{0}^{\infty} \int_{0}^{\infty} \cdots \int_{0}^{\infty}
\end{array}
$$

where

$$
\begin{aligned}
& \mathrm{r}_{\mathrm{i}}=\left[\mu\left(\mathrm{F}_{\mathrm{i}}\right)\right]^{1 / 2} ; \quad \mathrm{s}_{\mathrm{i}}=\left[\mu\left(\mathrm{C}_{\mathrm{j}}\right)\right]^{1 / 2} \\
& \Delta=\mathrm{r}_{1}+\cdots+\mathrm{r}_{\mathrm{m}}+\mathrm{s}_{1}+\cdots+\mathrm{s}_{\mathrm{n}}
\end{aligned}
$$

It remains to establish four inequalities ((16) through (19) below). 


$$
\begin{gathered}
\int_{0}^{\infty} e^{-\varepsilon_{i} x_{i}}\left[1-F_{i}, 2\left(x_{i}\right)\right] \cdots\left[1-F_{i}, b_{i}\left(x_{i}\right)\right] d F_{i, 1}\left(x_{i}\right) \\
\leq \rho\left(F_{i}\right)
\end{gathered}
$$

$$
\begin{aligned}
& \int_{0}^{r_{i}} e^{-\varepsilon_{i} x_{i}}\left[1-F_{i, 2}\left(x_{i}\right)\right] \ldots\left[1-F_{i,} b_{i}\left(x_{i}\right)\right] d F_{i, 1}\left(x_{i}\right) \\
& =\int_{0}^{\infty} e^{-\varepsilon_{i} x_{i}}\left[1-F_{i, 2}\left(x_{i}\right)\right] \cdots\left[1-F_{i}, b_{i}\left(x_{i}\right)\right] d F_{i, 1}\left(x_{i}\right) \\
& \quad-\frac{\rho\left(F_{i}\right)}{\rho\left(F_{i}\right)} \times \\
& \int_{r_{i}}^{\infty} e^{-\varepsilon_{i} x_{i}}\left[1-F_{i, 2}\left(x_{i}\right)\right] \cdots\left[1-F_{i, b_{i}}\left(x_{i}\right)\right] d F_{i, 1}\left(x_{i}\right) \\
& \quad \geq \rho\left(F_{i}\right)\left[1-\frac{\mu^{2}\left(F_{i}\right)+\sigma^{2}\left(F_{i}\right)}{r_{i}^{2}}\right] \\
& \int_{0}^{\infty} \alpha_{j} e^{-\alpha_{j} y_{j}} e^{-\beta_{j} y_{j}} \\
& {\left[1-G_{j, 1}\left(y_{j}\right)\right] \cdots\left[1-G_{j,} c_{j}\left(y_{j}\right)\right] d y_{j}} \\
& \leq \alpha_{j} \mu\left(C_{j}\right)
\end{aligned}
$$

$$
\begin{aligned}
& \int_{0}^{s} \alpha_{j} e^{-\alpha_{j} y_{j}} e^{-\beta_{j} y_{j}} \\
& {\left[1-G_{j, 1}\left(y_{j}\right)\right] \cdots\left[1-G_{j, c_{j}}\left(y_{j}\right)\right] d y_{j}} \\
& =\alpha_{j} \int_{0}^{\infty} e^{-\alpha_{j} y_{j}} e^{-\beta_{j} y_{j}} \\
& {\left[1-G_{j}, 1\left(y_{j}\right)\right] \ldots\left[1-G_{j,} c_{j}\left(y_{j}\right)\right] d y_{j}} \\
& -\alpha_{j} \int_{s_{j}}^{\infty}\left\{e^{-\alpha_{j} y_{j}} e^{-\beta_{j} y_{j}}\right. \\
& \left.\quad\left[1-G_{j, 1}\left(y_{j}\right)\right] \cdots\left[1-G_{j, c_{j}}\left(y_{j}\right)\right]\right\} d y_{j} \\
& \geq \alpha_{j} \mu\left(C_{j}\right)-\alpha_{j} \int_{s_{j}}^{\infty}\left\{\frac{\mu^{2}\left(C_{j}\right)+\sigma^{2}\left(C_{j}\right)}{y_{j}^{2}}\right\} d y_{j} \\
& \geq \alpha_{j}\left[\mu\left(C_{j}\right)-\frac{\mu^{2}\left(C_{j}\right)+\sigma^{2}\left(C_{j}\right)}{s_{j}}\right]
\end{aligned}
$$

The theorem is proved by substituting these inequalities into the previous inequalities for $\mathrm{D}(\mathrm{T})$.

\section{Estimating Diagnostic-Coverage LEVELS}

The previous section establishes what needs to be observed about system recovery given that system recovery occurs. It is another matter to establish that system recovery will occur.

For the most part, for the reasons discussed in the subsection above on diagnostic-coverage, this paper takes a strict attitude towards system recovery -if the system does not successfully recover within a specified period of time, it is considered a system failure. For illustrative purposes, this requirement is relaxed in one of the subsections describing experiments for the fourplex in section eight.

For diagnostic-coverage, any one trial has an outcome of either success or failure. Hence, the probability distribution is binomial. Let the probability of failure during a single trial be $p$. We wish to show that $p$ is small at a high confidence level. Let NF be the number of failures observed during $\mathrm{n}$ trials. The probability that there are no failures during an experiment consisting of $n$ trials is 


$$
\mathrm{P}\{\mathrm{NF}=0\}=(1-\mathrm{p})^{\mathrm{n}}
$$

The larger the value of $p$, the smaller the probability that no failures will be observed. Hence, this expression will yield a one-sided confidence interval. That is, if no failures appear during a large number of trials, then the likelihood that the probability of failure $p$ is greater than or equal to a certain quantity is very small. For a given probability $\mathrm{p}$ and a given confidence level $1-\gamma$, the number of trials required is given by the equation

$$
(1-p)^{n}=\gamma
$$

which gives

$$
\mathrm{n}=(\log \gamma) /(\log (1-\mathrm{p}))
$$

Some sample calculations follow.

For $\mathrm{p}=1 \mathrm{e}-6$ and $\gamma=1 \mathrm{e}-6, \mathrm{n}=1.3816 \mathrm{e}+7$
For $\mathrm{p}=1 \mathrm{e}-9$ and $\gamma=1 \mathrm{e}-11, \mathrm{n}=2.533 \mathrm{e}+10$

The binomial expression can be extended to handle failures during the trials. For example, the probability of zero or one failure during $\mathrm{n}$ trials is

$$
\mathrm{P}\{\mathrm{NF}=0 \text { or } 1\}=(1-\mathrm{p})^{\mathrm{n}}+\mathrm{np}(1-\mathrm{p})^{\mathrm{n}-1}
$$

For zero or one failure, establishing reliability when $\mathrm{p}=$ $1 \mathrm{e}-6$ and $\gamma=1 \mathrm{e}-6$ requires that $\mathrm{n}=16.7 \mathrm{e} 6$.

\section{ANALySis OF A FOURPLEX}

\section{Description of the System and Requirement}

The system is a reconfigurable fourplex where each module has a failure rate of $1 \mathrm{e}-3 /$ hour. The reliability requirement is a probability of failure of less than 1e-6 during a one hour operating period.

The experimental requirement is to establish this at the $100(1-1 \mathrm{e}-6) \%$ confidence level.

\section{Description of the Model}

The model for a reconfigurable fourplex is

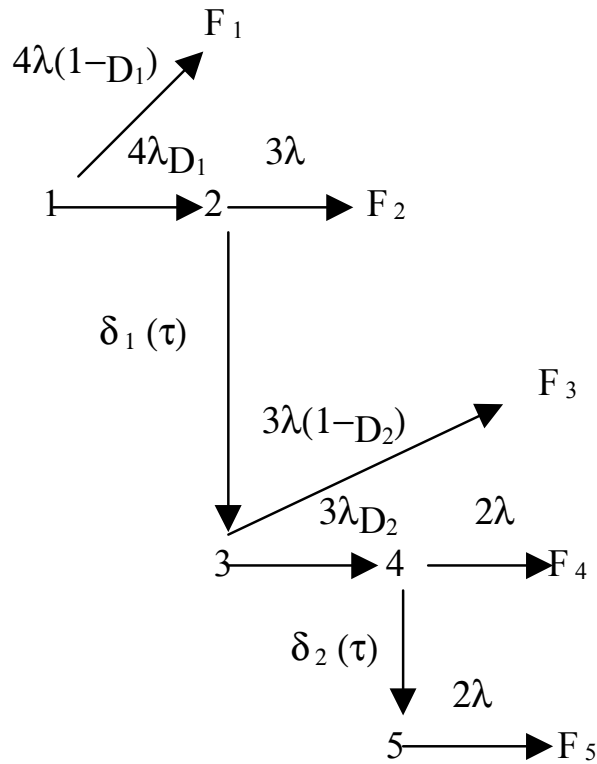

Figure 3 - Initial Model for a Reconfigurable Fourplex

By the theorems in the previous section, approximate probabilities (upper bounds) for the failure states at time $\mathrm{T}$ are, with $\lambda=1 \mathrm{e}-3 /$ hour and $\mathrm{T}=1$ hour,

$$
\begin{aligned}
& \mathrm{F}_{1}(\mathrm{~T})=4 \lambda\left(1-\mathrm{D}_{1}\right) \mathrm{T}=(4 \mathrm{e}-3)\left(1-\mathrm{D}_{1}\right) \\
& \mathrm{F}_{2}(\mathrm{~T})=12 \lambda^{2} \mathrm{~T} \mu\left(\delta_{1}\right)=(1.2 \mathrm{e}-5) \mu\left(\delta_{1}\right) \\
& \mathrm{F}_{3}(\mathrm{~T})=6 \lambda^{2}\left(1-\mathrm{D}_{2}\right) \mathrm{T}^{2}=(6 \mathrm{e}-6)\left(1-\mathrm{D}_{2}\right) \\
& \mathrm{F}_{4}(\mathrm{~T})=12 \lambda^{3} \mathrm{~T}^{2} \mu\left(\delta_{2}\right)=(1.2 \mathrm{e}-8) \mu\left(\delta_{2}\right) \\
& \mathrm{F}_{5}(\mathrm{~T})=4 \lambda^{3} \mathrm{~T}^{3}=4 \mathrm{e}-9
\end{aligned}
$$

The formulas above assume that testing goes well and the estimated value for the D's is one. The formulas use experimentally derived upper bounds for (1-D) and $\mu(\delta)$.

\section{Designing the Experiment}

Constraints for the design of the experiment are the component failure rate and the average recovery time. If the system is well designed, additional testing can lower the bound for lack of diagnostics (lack of coverage), but testing cannot change system recovery time or failure due to exhaustion of parts. Assume that preliminary testing has shown that system recovery takes about one second. The values for $\mathrm{F}_{2}, \mathrm{~F}_{4}$, and $\mathrm{F}_{5}$ become

$$
\begin{aligned}
& \mathrm{F}_{2}(\mathrm{~T})=12 \lambda^{2} \mathrm{~T} \mu\left(\delta_{1}\right)=3.33 \mathrm{e}-9 \\
& \mathrm{~F}_{4}(\mathrm{~T})=12 \lambda^{3} \mathrm{~T}^{2} \mu\left(\delta_{2}\right)=3.33 \mathrm{e}-12 \\
& \mathrm{~F}_{5}(\mathrm{~T})=4 \lambda^{3} \mathrm{~T}^{3}=4.00 \mathrm{e}-9
\end{aligned}
$$


Since the first failure state has a single step to failure, it must be assigned a significant portion of the 1e- 6 allotment in order to reduce the number of trials. Hence, a proposed assignment is given in table 1

Table 1 - Assignment of Failure Probabilities

\begin{tabular}{|l|l|}
\hline $\begin{array}{l}\text { Failure } \\
\text { State }\end{array}$ & $\begin{array}{l}\text { Proposed } \\
\text { Probability }\end{array}$ \\
\hline $\mathrm{F}_{1}$ & $\leq 0.9900 \mathrm{e}-6$ \\
\hline $\mathrm{F}_{2}$ & $\leq 0.0040 \mathrm{e}-6$ \\
\hline $\mathrm{F}_{3}$ & $\leq 0.0015 \mathrm{e}-6$ \\
\hline $\mathrm{F}_{4}$ & $\leq 0.0005 \mathrm{e}-6$ \\
\hline $\mathrm{F}_{5}$ & $\leq 0.0040 \mathrm{e}-6$ \\
\hline
\end{tabular}

Solving for the (1-D)'s in the formulas

$$
\begin{aligned}
\mathrm{F}_{1}(\mathrm{~T}) & =4 \lambda\left(1-\mathrm{D}_{1}\right) \mathrm{T} \\
= & (4 \mathrm{e}-3)\left(1-\mathrm{D}_{1}\right) \leq 0.9900 \mathrm{e}-6 \\
\mathrm{~F}_{3}(\mathrm{~T}) & =6 \lambda^{2}\left(1-\mathrm{D}_{2}\right) \mathrm{T}^{2} \\
= & (6 \mathrm{e}-6)\left(1-\mathrm{D}_{2}\right) \leq 0.0015 \mathrm{e}-6
\end{aligned}
$$

gives $\left(1-\mathrm{D}_{1}\right) \leq 2.475 \mathrm{e}-4$ and $\left(1-\mathrm{D}_{2}\right) \leq 2.500 \mathrm{e}-4$. These inequalities can be established at the 100(1 $0.25 \mathrm{e}-6) \%$ confidence level by 61,414 and 60,780 successful trials respectively.

It remains to show that the number of trials needed to establish the bounds for $1-\mathrm{D}_{1}$ and $1-\mathrm{D}_{2}$ permit establishing the bounds for $\mathrm{F}_{2}$ and $\mathrm{F}_{4}$ assigned in table 1. Assume that the mean recovery time is one second as indicated by preliminary experiments. For the standard normal (mean equal to 0 and standard deviation equal to 1) there is less than 0.25 e- 6 chance of being 5.025 standard deviations above the mean. If $\mathrm{s}_{1}$ and $\mathrm{s}_{2}$ are the sample standard deviations for the first and second recoveries, then $\frac{\mathrm{s}_{1}}{\sqrt{61414}}$ and $\frac{\mathrm{s}_{2}}{\sqrt{60780}}$ are the standard deviations for the estimates for the means. The requirements are

$$
\begin{aligned}
& 12 \lambda^{2}\left[\frac{1}{3600}+\frac{5.025 \mathrm{~s} 1}{\sqrt{61414}}\right] \leq 4 \mathrm{e}-9 \\
& 12 \lambda^{3}\left[\frac{1}{3600}+\frac{5.025 \mathrm{~s} 2}{\sqrt{60780}}\right] \leq 1.5 \mathrm{e}-9
\end{aligned}
$$

Solving gives $\mathrm{s}_{1} \leq 9.86$ seconds and $\mathrm{s}_{2} \leq 2.2 \mathrm{e}+4$ seconds. In experiments nothing is certain, but these computations indicate that the experiment will establish the bounds for $\mathrm{F}_{2}$ and $\mathrm{F}_{4}$ assigned in table 1 unless the system recoveries have very large standard deviations.

In summary, if the system performs well and if the first and second moments for the system recoveries are not too large, then 61,414 fault injections into the fourplex and 60,780 fault injections into the threeplex will establish that the system has less than 1e-6 chance of failure at the $100(1-1 \mathrm{e}-6) \%$ confidence level.

\section{Accuracy of the Upper Bound Approximation}

Since the experiment has been designed using the upper bound from section six, objections can be made if this bound is not accurate. An upper bound that is too large increases the number of trials that must be performed. This subsection computes the upper and lower bounds for the five failure states in figure 3 . The parameters are $D_{1}$ $=1-2.475 \mathrm{e}-4, \mathrm{D}_{2}=1-2.500 \mathrm{e}-4, \lambda=0.001 /$ hour, and time $\mathrm{T}=$ one hour. Assume both system recovery distributions have a mean and standard deviation of one second. The upper and lower bounds are given in table 2

Table 2 - Accuracy of the Bounds for the Fourplex

\begin{tabular}{|l|l|l|}
\hline & lower bound & upper bound \\
\hline$F_{1}$ & $0.988 \mathrm{e}-6$ & $0.990 \mathrm{e}-6$ \\
\hline $\mathrm{F}_{2}$ & $0.316 \mathrm{e}-8$ & $0.333 \mathrm{e}-8$ \\
\hline $\mathrm{F}_{3}$ & $0.145 \mathrm{e}-8$ & $0.150 \mathrm{e}-8$ \\
\hline $\mathrm{F}_{4}$ & $0.311 \mathrm{e}-11$ & $0.333 \mathrm{e}-11$ \\
\hline $\mathrm{F}_{5}$ & $0.360 \mathrm{e}-8$ & $0.400 \mathrm{e}-8$ \\
\hline & & \\
\hline Total & $0.996 \mathrm{e}-6$ & $0.999 \mathrm{e}-6$ \\
\hline
\end{tabular}

The upper bound is accurate enough for the design of the experiment above.

\section{Lowering the Diagnostic-Coverage Requirement}

This subsection considers making more of a distinction between diagnostics (coverage) and reliability. This distinction, as used below, permits reducing the number of fault injections, but it has two disadvantages. One disadvantage is that it requires a benign assumption about faults that are not quickly detected. The assumption is that the undetected fault is benign enough that it alone cannot cause the system to fail. System failure is said to occur when another fault arrives and the majority voter is potentially overwhelmed. The other disadvantage is that subsequent missions are at greater risk. The lower diagnostic requirement allows a quicker buildup of faults that can potentially overwhelm the system. (As mentioned before, this is studied in [57].) The model for the lower requirement is given in figure 4. 


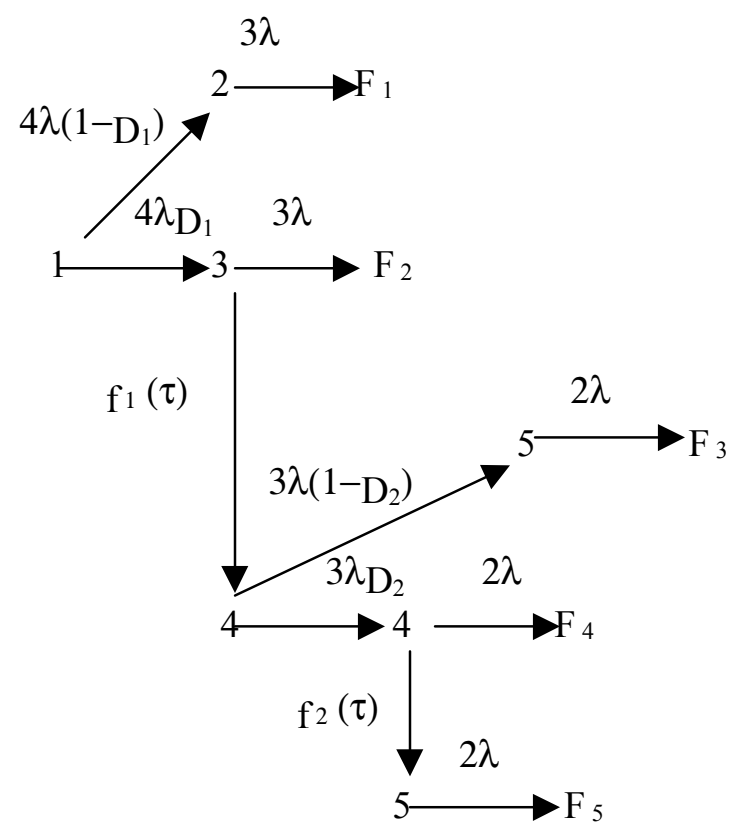

Figure 4 - Modified Model for the Fourplex

The upper bounds for being in the failure states by time $\mathrm{T}$ are given below. As before, it is assumed that preliminary experiments have given estimates of one second for the means and standard deviations of the system recovery functions. If at least 100 trials are performed to obtain the preliminary estimates for the recovery functions, then the $100(1-0.25 e-6) \%$ confidence for the means is given by

$$
\text { one second }+\frac{5.025 \text { (one second) }}{\sqrt{100}} \approx 1.5 \text { second }
$$

Using this value for $\mu\left(f_{1}\right)$ and $\mu\left(f_{2}\right)$ gives

$$
\begin{aligned}
& \mathrm{F}_{1}(\mathrm{~T})=6 \lambda^{2}\left(1-\mathrm{D}_{1}\right) \mathrm{T}^{2}=(6 \mathrm{e}-6)\left(1-\mathrm{D}_{1}\right) \\
& \mathrm{F}_{2}(\mathrm{~T})=12 \lambda^{2} \mathrm{~T} \mu\left(\mathrm{f}_{1}\right)=(1.2 \mathrm{e}-5) \mu\left(\mathrm{f}_{1}\right)=5 \mathrm{e}-9 \\
& \mathrm{~F}_{3}(\mathrm{~T})=4 \lambda^{3}\left(1-\mathrm{D}_{2}\right) \mathrm{T}^{3}=(4 \mathrm{e}-9)\left(1-\mathrm{D}_{2}\right) \\
& \mathrm{F}_{4}(\mathrm{~T})=12 \lambda^{3} \mathrm{~T}^{2} \mu\left(\mathrm{f}_{2}\right)=(1.2 \mathrm{e}-8) \mu\left(\mathrm{f}_{2}\right)=5 \mathrm{e}-12 \\
& \mathrm{~F}_{5}(\mathrm{~T})=4 \lambda^{3} \mathrm{~T}^{3}=4 \mathrm{e}-9
\end{aligned}
$$

Letting $\mathrm{D}_{2}=0$ gives a total of 13.005 e- 9 for the last four failure modes. Since $\mathrm{D}_{2}$ does not need to be estimated, it remains to show that

$$
\begin{aligned}
& (6 e-6)\left(1-D_{1}\right) \leq(1 e-6-13.005 e-13) \\
& \text { or }\left(1-D_{1}\right) \leq 0.16
\end{aligned}
$$

at the $100(1-0.5 e-6) \%$ confidence level. This requires 83 trials provided the system detects and recovers from all the injected faults.

\section{DESCRIPTION OF THE SEVENPLEX}

\section{General Description}

The architecture is a nonreconfigurable sevenplex where each module consists of a computer-on-a-chip plus six transmission lines to the other modules. There are seven computers and forty two links.

Table 3 - Device Failure Rates

\begin{tabular}{|l|l|l|}
\hline \multicolumn{1}{|c|}{ Device } & Permanent Rate & Transient Rate \\
\hline computer & 1 e-6 per hour & 1 e-5 per hour \\
\hline line & 1 e-5 per hour & 1 e- 4 per hour \\
\hline
\end{tabular}

The permanent fault rate for the system is $0.00427 /(10$ hours); the transient rate is $0.0427 /(10$ hours $)$; and the total rate is $0.04697 /(10$ hours $)$.

\section{Arguments from Design and Tests}

The motivation for conducting arguments-from-design and tests comes from the previous analysis of the fourplex where most of the trials were for establishing the diagnostic-coverage requirement. Arguments and tests that say the system can detect and survive the initial faults can reduce the experimental effort.

There are general principles for arguments-from-design, but the actual demonstrations appear to be system dependent. The two key elements are: (1) $3 \mathrm{k}+1$ components are needed to reach consensus in the presence of $\mathrm{k}$ (arbitrarily malicious) faults and (2) any message from a good component can be identified as being from that component.

For both diagnostics and Byzantine resilience, this sevenplex has the following features.

(i) The computational and decision making components are computers-on-a-chip. The faults (input-output malfunctions) appear on the output registers, and any incorrect output will be transmitted to another computer.

(ii) Communication is point-to-point for all the computers. Hence, any good computer knows from which computer it received an incorrect message. It can, however, require some time to determine if the incorrect message arises from a faulty computer or a faulty link.

With the above in mind, we assume that tests and arguments-from-design have established the following. 
The system can tolerate and correctly identify the faulty components as long as there are no more than two faulty components currently in the system.

The tests and arguments have not identified the time it takes to detect and identify the faulty units, nor do they make any assertions about system behavior if three or more faults are present. This part belongs to the experimental effort.

\section{Requirement}

The requirement is to establish that there is less than one chance in a billion of failure during a ten hour flight, and to establish this at the $100(1-1 \mathrm{e}-9) \%$ confidence level.

\section{THE PATH SPACE MODEL AND DESIGN OF THE EXPERIMENT FOR THE SEVENPLEX}

The construction of the model and the design of the experiment are intertwined. There are three steps.

1. Preliminary experiments are conducted to get initial estimates of the model parameters.

2. These initial estimates are used to construct a model.

3. The model is used to determine the number and types of fault injections required.

There is a fourth step that is not covered in this paper.

4. The fault injections are performed, and the parameters and their confidence intervals are computed.

If the first three steps are done adequately and if the system is well designed (the fault injection results are as expected) then this four step procedure will establish that the system has the given reliability at the required confidence level.

\section{Preliminary Experiments}

Typically an experiment is designed after preliminary experiments that yield preliminary estimates of the parameters and their variance. In this approach, the model also is constructed after preliminary experiments since the goal of model construction is to produce a model that is conservative and that is efficient with respect to experimental requirements. Both of these properties depend on the estimated parameter values.

Assume the preliminary values for system recovery for the four types of faults are given in table 4 . Recovery from a computer transient takes longer because of the need to rewrite the internal stored values.

Table 4 - Preliminary Results from Single Fault Injections

\begin{tabular}{|l|l|}
\hline $\begin{array}{l}\text { Type of } \\
\text { fault }\end{array}$ & $\begin{array}{l}\text { mean } \\
\text { standard dev }\end{array}$ \\
\hline $\begin{array}{l}\text { computer } \\
\text { permanent }\end{array}$ & $\begin{array}{l}\mu=4 \mathrm{secs} \\
\sigma=1 \mathrm{sec}\end{array}$ \\
\hline $\begin{array}{l}\text { computer } \\
\text { transient }\end{array}$ & $\mu=8 \mathrm{secs}$ \\
\hline link & $\mu=4 \mathrm{sec}$ \\
permanent & $\sigma=1 \mathrm{sec}$ \\
\hline link & $\mu=4 \mathrm{secs}$ \\
transient & $\sigma=1 \mathrm{sec}$ \\
\hline
\end{tabular}

Suppose double fault injections yield the results in table 5.

Table 5 - Preliminary Results from Double Fault Injections

\begin{tabular}{|l|l|}
\hline Faults present & $\begin{array}{l}\text { mean } \\
\text { standard dev }\end{array}$ \\
\hline $\begin{array}{l}\text { computer permanent } \\
\text { computer permanent }\end{array}$ & $\begin{array}{l}\mu=8 \mathrm{secs} \\
\sigma=2 \mathrm{sec}\end{array}$ \\
\hline $\begin{array}{l}\text { computer permanent } \\
\text { computer transient }\end{array}$ & $\mu=8 \mathrm{secs}$ \\
\hline computer permanent & $\mu=2 \mathrm{sec}$ \\
link permanent & $\sigma=2 \mathrm{sec}$ \\
\hline computer permanent & $\mu=8 \mathrm{secs}$ \\
link transient & $\sigma=2 \mathrm{sec}$ \\
\hline computer transient & $\mu=12 \mathrm{secs}$ \\
computer permanent & $\sigma=3 \mathrm{sec}$ \\
\hline computer transient & $\mu=16 \mathrm{secs}$ \\
computer transient & $\sigma=4 \mathrm{sec}$ \\
\hline computer transient & $\mu=12 \mathrm{secs}$ \\
link permanent & $\sigma=3 \mathrm{sec}$ \\
\hline computer transient & $\mu=12 \mathrm{secs}$ \\
link transient & $\sigma=3 \mathrm{sec}$ \\
\hline
\end{tabular}

The model will be constructed and the experiment designed on the assumption that the parameters in the above two tables are reasonable accurate. If these parameters are too large, then the model and experiment will be inefficient. If these parameters are too small, then the model and experiment will not be adequate.

\section{Constructing the Model}

A explicit model would have several hundred states. Hence, we use a generic path model where each path in the diagram represents several actual paths. This approach pivots on whether a fault occurrence is transient 
or permanent. Transient faults occur more frequently, but permanent faults remain in the system. The notation is

$\theta_{\mathrm{i}}$ the first fault in a path

$\phi_{i}$ the second fault in a path

$\rho_{i}$ the third fault in a path

$\varepsilon_{i}$ the fourth fault in a path

$i$ the index: $p=$ permanent; $t=$ transient

$\omega$ arbitrary fault occurrence with rate $=46.97 \mathrm{e}-4 /$ hour

$\pi$ the diagnostic-coverage probability

For example, the generic path in the diagram with states $1,2,4$, and $F_{2}$ represents four actual paths with their four different fault occurrences

computer permanent - computer transient

computer permanent - link transient

link permanent - computer transient

link permanent - link transient

As mentioned before, the model in figures 5 through 8 is not unique. It tries to optimize two properties: (1) it is conservative (overestimates the probability of system failure), but not too conservative and (2) it can be verified with a minimum experimental effort. The model in figures 5 through 8 is the result of an iterative process with the constant calculation and recalculation of reliability and experimental effort.

\section{Design of the experiment}

Since each path in the model above is a generic path representing several actual paths, each recovery in the model above represents several actual recoveries. The number of actual recoveries represented for each generic recovery is given in table 6

Suppose 100 fault injections are made for each of the 134 recoveries. This implies the standard deviation for the estimate for the mean is $1 / 10$ the population standard deviation. Computations for the model above use a value of the estimated mean plus 10 standard deviations. The values used in the model are given in tables 7 and 8 .

The confidence level for each recovery transition is given by the tail of the normal distribution.

$$
\int_{10}^{\infty} \frac{e^{-x^{2} / 2}}{\sqrt{2 \pi}} d x=7.7 e-24
$$

The 134 transitions require 13,400 fault injections and create a drop in confidence of $134(7.7 \mathrm{e}-24)=1 \mathrm{e}-21$.
Table 6 - Actual Recoveries for Each Generic Recovery

\begin{tabular}{|l|l|l|l|}
\hline $\begin{array}{l}\text { Recovery } \\
\text { transition } \\
\text { label }\end{array}$ & $\begin{array}{l}\text { Number } \\
\text { of } \\
\text { recoveries }\end{array}$ & $\begin{array}{l}\text { Recovery } \\
\text { transition } \\
\text { label }\end{array}$ & $\begin{array}{l}\text { Number } \\
\text { of } \\
\text { recoveries }\end{array}$ \\
\hline $\mathrm{H}_{1}$ & 2 & $\mathrm{H}_{12}$ & 16 \\
\hline $\mathrm{H}_{2}$ & 4 & $\mathrm{H}_{13}$ & 16 \\
\hline $\mathrm{H}_{3}$ & 8 & $\mathrm{H}_{14}$ & 8 \\
\hline $\mathrm{H}_{4}$ & 4 & $\mathrm{H}_{15}$ & 4 \\
\hline $\mathrm{H}_{5}$ & 8 & $\mathrm{H}_{16}$ & 8 \\
\hline $\mathrm{H}_{6}$ & 2 & $\mathrm{H}_{17}$ & 8 \\
\hline $\mathrm{H}_{7}$ & 4 & $\mathrm{H}_{18}$ & 8 \\
\hline $\mathrm{H}_{8}$ & 4 & $\mathrm{H}_{19}$ & 4 \\
\hline $\mathrm{H}_{9}$ & 4 & $\mathrm{H}_{20}$ & 8 \\
\hline $\mathrm{H}_{10}$ & 8 & $\mathrm{H}_{21}$ & 8 \\
\hline $\mathrm{H}_{11}$ & 8 & & \\
\hline & & total & 134 actual recoveries \\
\hline
\end{tabular}

Table 7 - Upper Bounds for Single Fault Recoveries

\begin{tabular}{|l|l|}
\hline Type of fault & $\begin{array}{l}\text { upper bound for } \\
\text { recovery time }\end{array}$ \\
\hline computer permanent & $\mu=5$ secs \\
\hline computer transient & $\mu=10$ secs \\
\hline link permanent & $\mu=5$ secs \\
\hline link transient & $\mu=5$ secs \\
\hline
\end{tabular}

Table 8 - Upper Bounds for Double Fault Recoveries

\begin{tabular}{|l|l|}
\hline Faults present & $\begin{array}{l}\text { upper bound for } \\
\text { recovery time }\end{array}$ \\
\hline comp perm - comp perm & $\mu=10$ secs \\
\hline comp perm - comp tran & $\mu=10$ secs \\
\hline comp perm - link perm & $\mu=10$ secs \\
\hline comp perm - link tran & $\mu=10$ secs \\
\hline comp tran - comp perm & $\mu=15$ secs \\
\hline comp tran - comp tran & $\mu=20$ secs \\
\hline comp tran - link perm & $\mu=15$ secs \\
\hline comp tran - link tran & $\mu=15$ secs \\
\hline
\end{tabular}




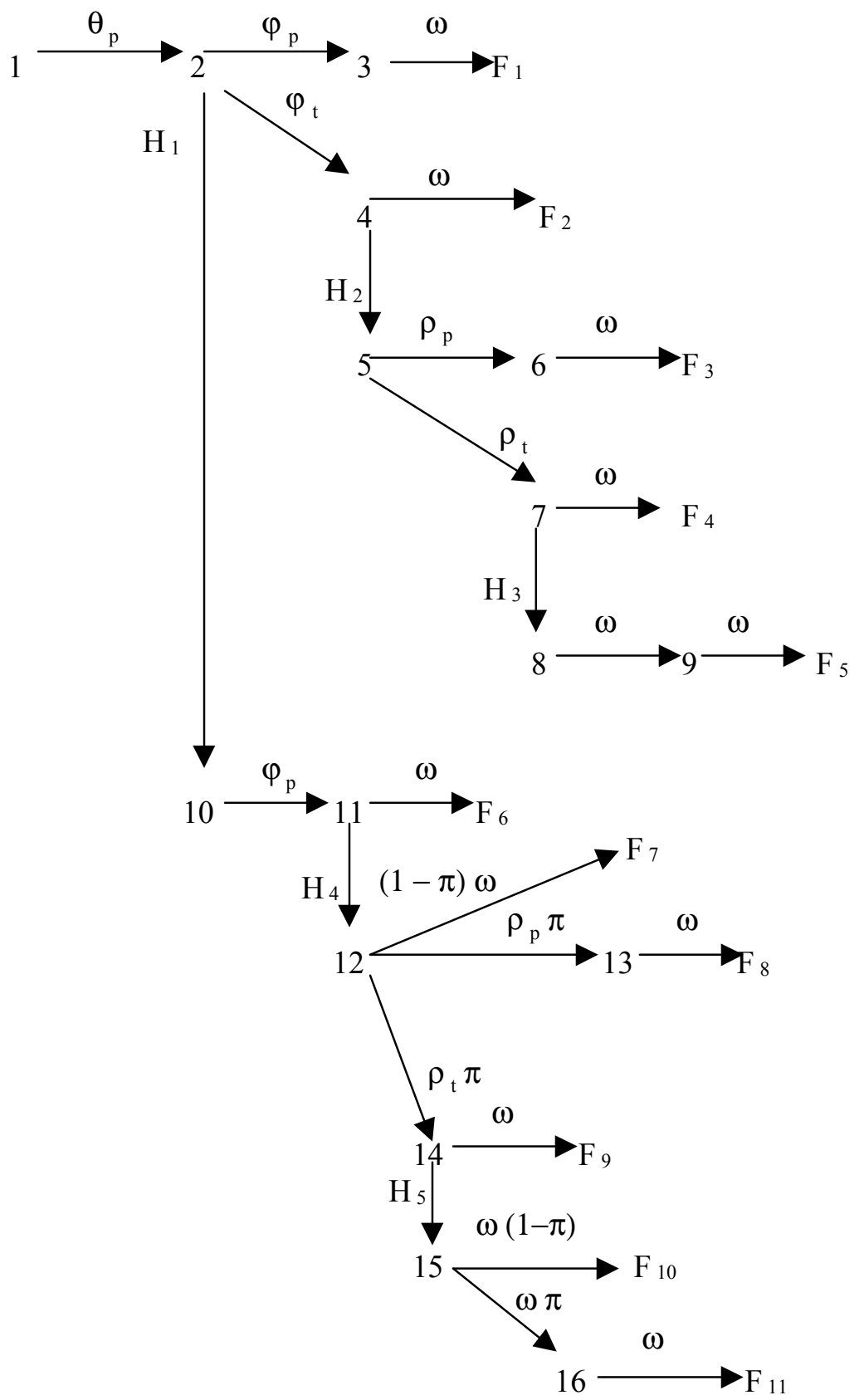

Figure 5 - Path Space Model for the Sevenplex (1/4) 


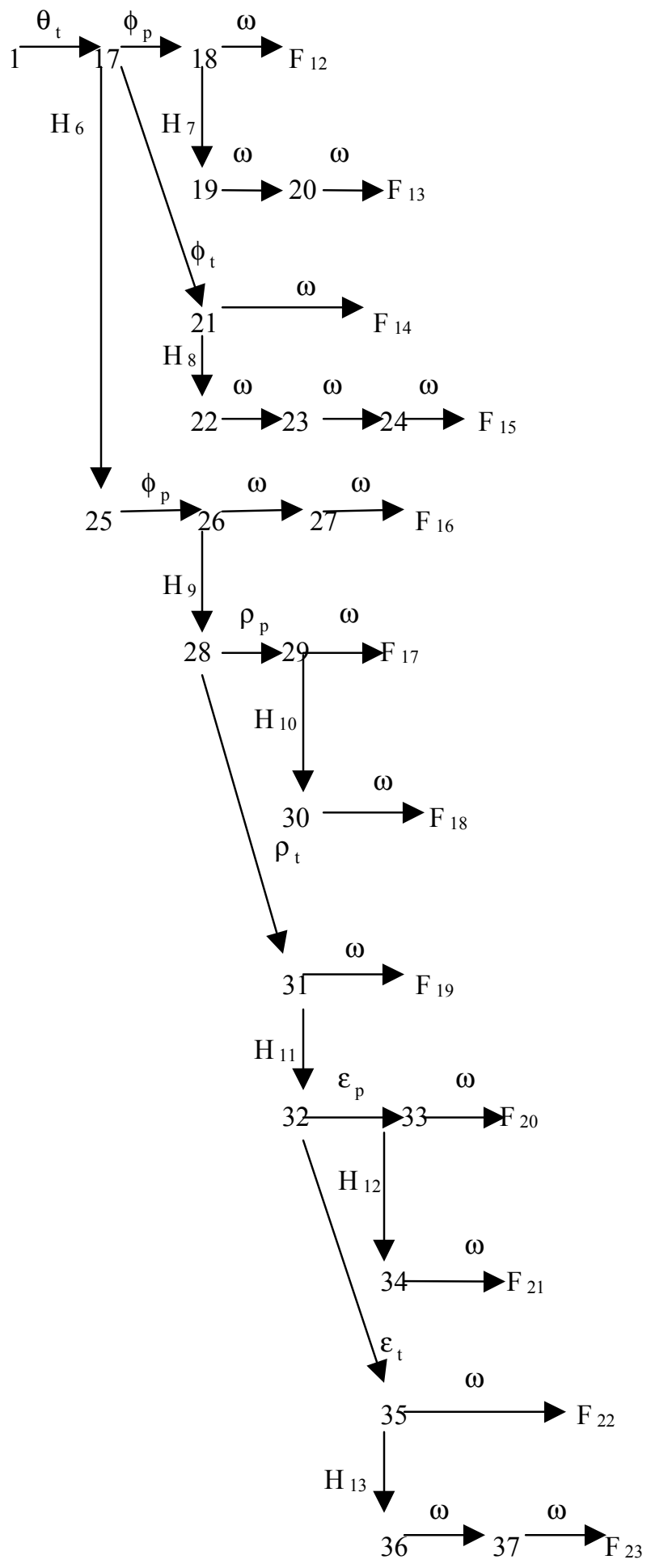

Figure 6 - Path Space Model for the Sevenplex (2/4) 


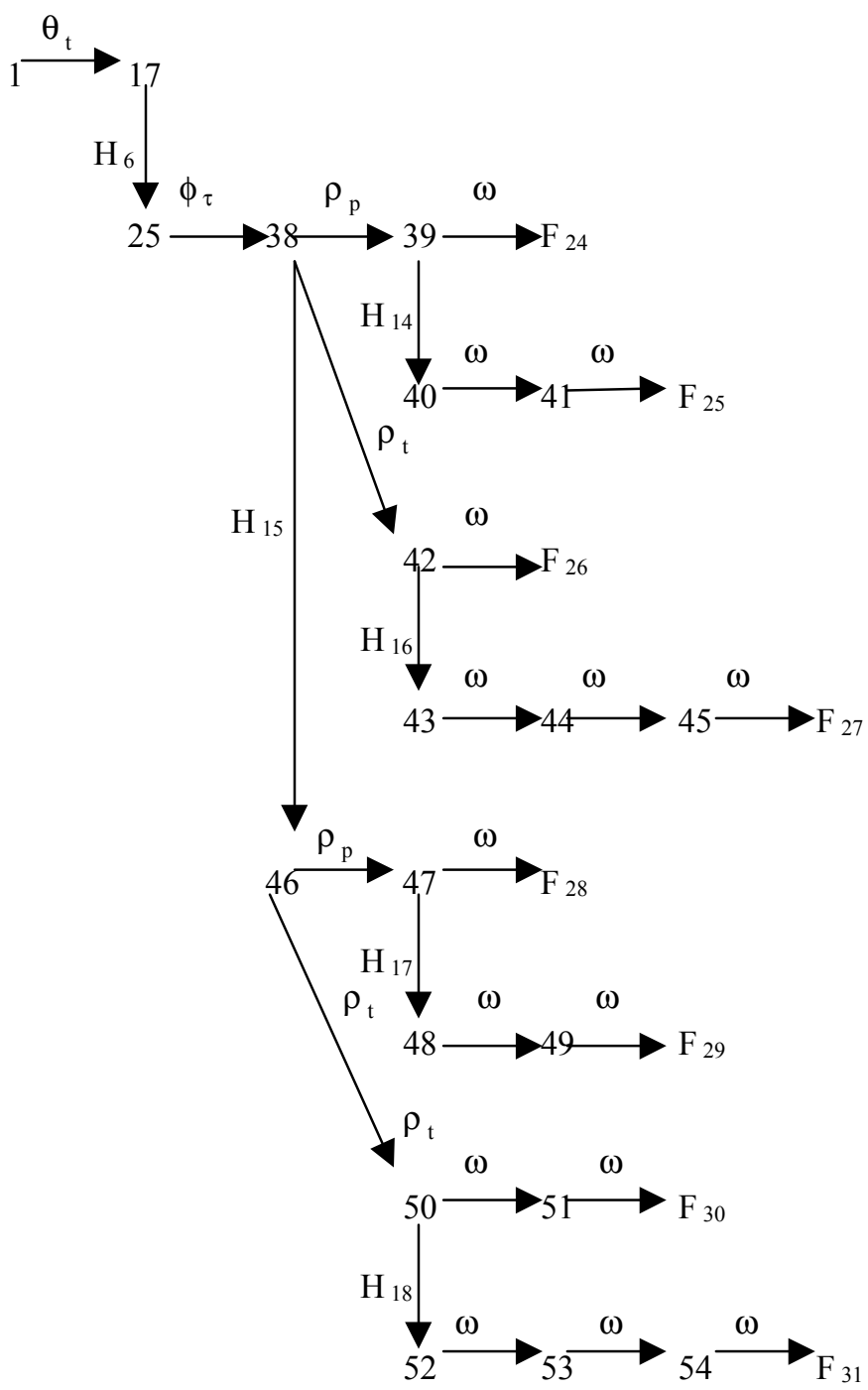

Figure 7 - Path Space Model for the Sevenplex (3/4) 


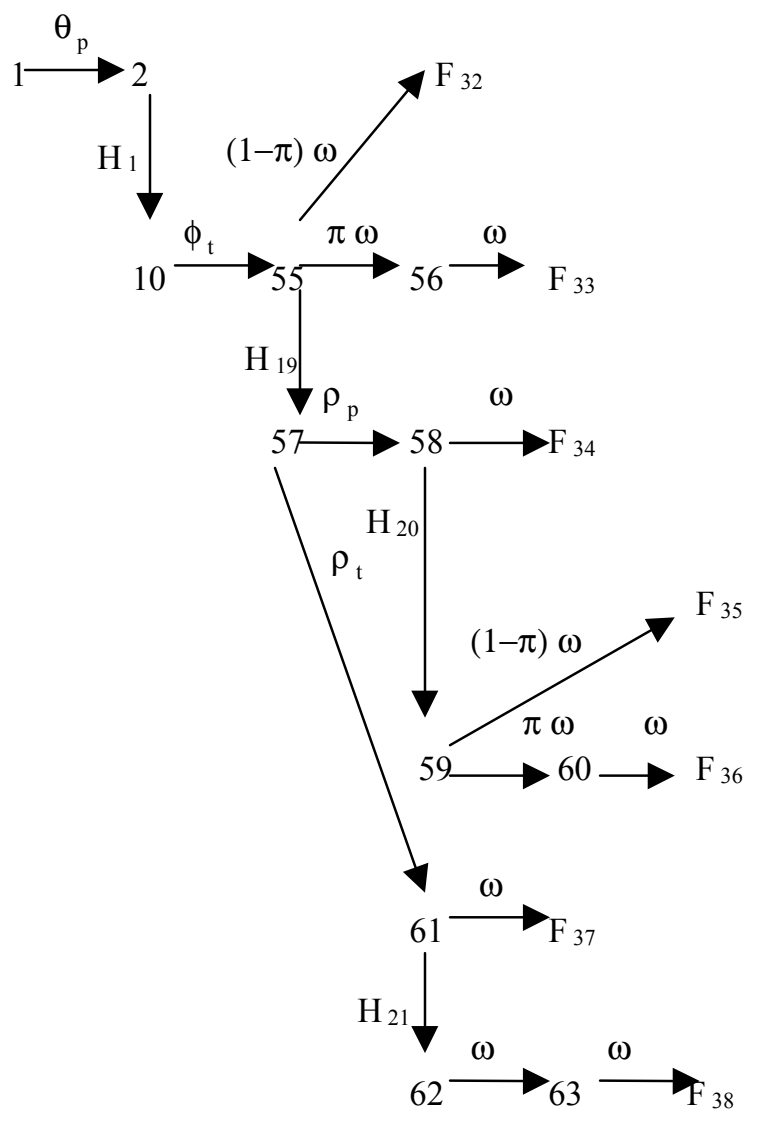

Figure 8 - Path Space Model for the Sevenplex (4/4)

Reliability Computation Based on Proposed Model

Table 9 shows the four paths to failure state $\mathrm{F}_{2}$ and the computation for each path. For the first and second columns, there is one failure transition that is not competing against system recovery. For the third and fourth columns, a failure transition is competing against a single fault recovery. For the fifth and sixth columns, a failure transition is competing against a double fault recovery. The entry in the fourth column and third row is $42 \mathrm{e}-4$ instead of $36 \mathrm{e}-4$ because the faulty computer has not yet been identified.

Table 9 - Computations for the Four Actual Paths to Failure State $F_{2}$

\begin{tabular}{|l|l|l|l|l|l|l|}
\hline $\mathrm{T} /(1 !)$ & $\theta_{\mathrm{p}}$ & $\mu_{1}$ & $\phi_{\mathrm{t}}$ & $\mu_{2}$ & $\omega$ & $\mathrm{P}\{\mathrm{F}\}$ \\
\hline 10 & $7 \mathrm{e}-6$ & $5 / 3600$ & $6 \mathrm{e}-5$ & $15 / 3600$ & $46.97 \mathrm{e}-4$ & $1.14 \mathrm{e}-16$ \\
\hline 10 & $7 \mathrm{e}-6$ & $5 / 3600$ & $42 \mathrm{e}-4$ & $10 / 3600$ & $46.97 \mathrm{e}-4$ & $5.33 \mathrm{e}-15$ \\
\hline 10 & $42 \mathrm{e}-5$ & $5 / 3600$ & $7 \mathrm{e}-5$ & $15 / 3600$ & $46.97 \mathrm{e}-4$ & $7.99 \mathrm{e}-15$ \\
\hline 10 & $42 \mathrm{e}-5$ & $5 / 3600$ & $41 \mathrm{e}-4$ & $10 / 3600$ & $46.97 \mathrm{e}-4$ & $3.12 \mathrm{e}-13$ \\
\hline total & & & & & & $3.25 \mathrm{e}-13$ \\
\hline
\end{tabular}


The results of the computations for all the failure states that are not failure states because of a diagnostic-coverage failure are given in Table 10

Table 10 - Computations for the Non-DiagnosticCoverage Failure States

\begin{tabular}{|l|l|l|l|}
\hline $\begin{array}{l}\text { Failure } \\
\text { State }\end{array}$ & Prob & $\begin{array}{l}\text { Failure } \\
\text { State }\end{array}$ & Prob \\
\hline 1 & $5.80 \mathrm{e}-11$ & 20 & $9.39 \mathrm{e}-15$ \\
\hline 2 & $3.25 \mathrm{e}-13$ & 21 & $1.35 \mathrm{e}-11$ \\
\hline 3 & $9.61 \mathrm{e}-13$ & 22 & $1.18 \mathrm{e}-14$ \\
\hline 4 & $3.41 \mathrm{e}-15$ & 23 & $3.58 \mathrm{e}-12$ \\
\hline 5 & $9.49 \mathrm{e}-14$ & 24 & $6.82 \mathrm{e}-15$ \\
\hline 6 & $5.80 \mathrm{e}-11$ & 25 & $9.82 \mathrm{e}-14$ \\
\hline 7 & diag-cov & 26 & $7.18 \mathrm{e}-14$ \\
\hline 8 & $1.39 \mathrm{e}-10$ & 27 & $9.27 \mathrm{e}-15$ \\
\hline 9 & $1.55 \mathrm{e}-12$ & 28 & $8.15 \mathrm{e}-12$ \\
\hline 10 & diag-cov & 29 & $1.40 \mathrm{e}-10$ \\
\hline 11 & $1.52 \mathrm{e}-11$ & 30 & $9.73 \mathrm{e}-14$ \\
\hline 12 & $3.41 \mathrm{e}-13$ & 31 & $1.08 \mathrm{e}-12$ \\
\hline 13 & $5.68 \mathrm{e}-13$ & 32 & diag-cov \\
\hline 14 & $3.29 \mathrm{e}-12$ & 33 & $2.77 \mathrm{e}-12$ \\
\hline 15 & $1.11 \mathrm{e}-12$ & 34 & $7.92 \mathrm{e}-13$ \\
\hline 16 & $9.31 \mathrm{e}-12$ & 35 & diag-cov \\
\hline 17 & $8.15 \mathrm{e}-13$ & 36 & $1.37 \mathrm{e}-11$ \\
\hline 18 & diag-cov & 37 & $8.06 \mathrm{e}-12$ \\
\hline 19 & $9.41 \mathrm{e}-12$ & 38 & $1.37 \mathrm{e}-10$ \\
\hline & & & $6.35 \mathrm{e}-10$ \\
\hline & Subtotal & &
\end{tabular}

The experimental effort required for the diagnosticcoverage failure states (states $7,10,18,32$, and 35) is displayed in table 11. For these computations an upper bound was placed on the probabilities of being in the failure states by summing the failure rates

\section{Summary for Construction of Model and Design of Experiment}

The analysis above proposes 13,400 trials to establish upper bounds for the recovery means and 32,160 trials to establish adequate diagnostic-coverage probabilities for a total of 45,560 fault injections. The drop in confidence from the recovery means is $1 \mathrm{e}-21$ and the drop in confidence from the diagnostic-coverage probabilities is 5e-10. If the trials go as predicted, this experiment and model will give an upper bound for the probability of failure of $8.29 \mathrm{e}-10$ with a confidence level of $100(1-5 \mathrm{e}-$ $10-1 \mathrm{e}-21) \%$.

\section{SUMMARY}

This paper has derived a result about a class of semiMarkov reliability models that are suitable for ultra reliable digital systems. These systems have extremely fast fault recovery. The new theorem has been used to solve the long standing problem of designing validation experiments for this class of systems.

Table 11 - Experiments and Computations for the Diagnostic-Coverage Failure States

\begin{tabular}{|l|l|l|l|l|}
\hline $\begin{array}{c}\text { Failure } \\
\text { State }\end{array}$ & $\begin{array}{l}\text { Upper bound for state } \\
\text { perm rate }=\alpha=42.7 \mathrm{e}-5 \\
\text { tran rate }=\beta=42.7 \mathrm{e}-4 \\
\text { total rate }=\omega=46.97 \mathrm{e}-4\end{array}$ & $\begin{array}{l}\text { Value } \\
\text { for } \\
(1-\pi)\end{array}$ & $\begin{array}{l}\text { Trials to } \\
\text { establish }(1-\pi) \\
\text { at the } \\
100(1-1 \mathrm{e}-10) \% \\
\text { level }\end{array}$ & $\begin{array}{l}\text { State } \\
\text { probability } \\
\text { for given } \\
(1-\pi)\end{array}$ \\
\hline 7 & $(1000 / 6) \alpha^{2} \omega(1-\pi)=(1-\pi) 1.38 \mathrm{e}-7$ & $1 \mathrm{e}-3$ & 23,000 & $1.38 \mathrm{e}-10$ \\
\hline 10 & $(10000 / 24) \alpha^{2} \beta \omega(1-\pi)=(1-\pi) 1.47 \mathrm{e}-9$ & $1 \mathrm{e}-2$ & 2,290 & $1.47 \mathrm{e}-11$ \\
\hline 18 & $(10000 / 24) \alpha^{2} \beta \omega(1-\pi)=(1-\pi) 1.47 \mathrm{e}-9$ & $1 \mathrm{e}-2$ & 2,290 & $1.47 \mathrm{e}-11$ \\
\hline 32 & $(100 / 2) \alpha \beta(10 / 3600) \omega(1-\pi)=(1-\pi) 1.17 \mathrm{e}-9$ & $1 \mathrm{e}-2$ & 2,290 & $1.17 \mathrm{e}-11$ \\
\hline 35 & $(10000 / 24) \alpha^{2} \beta \omega(1-\pi)=(1-\pi) 1.52 \mathrm{e}-9$ & $1 \mathrm{e}-2$ & 2,290 & $1.52 \mathrm{e}-11$ \\
\hline & & subtotal & 32,160 & $1.943 \mathrm{e}-10$ \\
\hline
\end{tabular}




\section{REFERENCES}

[1] Z. Alkhalifa, V. Nair, N. Krishnamurthy, J. Abraham, "Design and evaluation of system-level checks for on-line control flow error detection," IEEE Transactions on Parallel and Distributed Systems, volume 10 Issue 6 (1999), pp. 627-641.

[2] J. Ariat, M. Aguera, L. Amat, Y. Crouzet, J.-C. Fabre, J.-C. Laprie, E. Martins, D. Powell, "Fault injection for dependability validation: a methodology and some applications," IEEE transactions on Software Engineering, Volume 16 Issue 2 (1990), pp. 166-182.

[3] J. Ariat, M. Aguera, Y. Crouzet, J.-C. Fabre, E. Martins, D. Powell, "Experimental evaluation of the fault tolerance of an atomic multicast system," IEEE Transactions on Reliability, Volume 39 Issue 4 (1990), pp. 455-467.

[4] J. Ariat, J. Boue, Y. Crouzet, "Validation-based development of dependable systems," IEEE Micro, Volume 19 Issue 4 (1999), pp. 66-79.

[5] J. Ariat, A. Costes, Y. Crouzet, J.-C. Laprie, D. Powell, "Fault injection and dependability evaluation of fault-tolerant systems," IEEE Transactions on Computers, Volume 42 Issue 8 (1993), pp. 913-923.

[6] D. Avreesky, J. Arlat, J.-C. Laprie, Y. Crouzeet, "Fault injection for formal testing of fault tolerance," IEEE Transactions on Reliability, Volume 45 Issue 3 (1996), pp. 443-455.

[7] J. Barton, E. Czek, Z. Segall, D. Siewiorek, "Fault injection experiments using FIAT," IEEE Transactions on Computers, volume 39 Issue 4 (1990), pp. 575-582.

[8] A. Brombacher, I. van Beurdeu, "RIFIT: analyzing hardware and software in safeguarding systems," Reliability Engineering \& System Safety, Volume 66 Issue 2 (1999), pp. 149-156.

[9] J. Carreira, D. Costa, J. Silva, "Fault injection spotchecks computer system dependability," IEEE Spectrum, Volume 36 Issue 8 (1999), pp 50-55.

[10] P. Cascaval, S. Bennett, "Efficient march test for 3coupling faults in random access memories," Microprocessors and Microsystems, Volume 24 Issue 10 (2001), pp. 501-509.

[11] P. Cheynet, R. Velazco, S. Rezgui, L. Peters, K. Beck, R, Ecoffet, "Digital fuzzy control: a robust alternative suitable for space application," IEEE Transactions on Nuclear Science, Volume 45 Issue 6 (1998), pp. 2941-2947.
[12] G. Choi, R. Iyer, V. Carreno, "Simulated fault injection: a methodology to evaluate fault tolerant microprocessor architectures," IEEE Transactions on Reliability, Volume 39 Issue 4 (1990), pp. 486-491.

[13] J. Choi, P. Seong, "Dependability estimation of a digital system with consideration of software masking effects on hardware faults," Reliabiity Engineering \& System Safety, volume 71 Issue 1 (2001), pp. 45-55.

[14] J. Clark, D. Pradhan, "Fault injection: a method for validating computer-system dependability," Computer, Volume 28 Issue 6 (1995), pp. 47-56

[15] C. Constantinescu, "Using multi-stage and stratified sampling for inferring fault-coverage probabilities," IEEE transactions on Reliability, Volume 44 Issue4 (1995), pp. 632-639.

[16] C. Constantinescu, "Inferring coverage probabilities by optimum 3-stage sampling," Microelectronics and Reliability, Volume 37 Issue 8 (1998), page 1280.

1[7] C. Constantinescu, "Teraflops supercomputer: architecture and validation of the fault tolerant mechanisms," IEEE Transactions on Computers, Volume 49 Issue 9 (2000), pp. 886-894.

[18] M. Cukier, D. Powell, J. Ariat, "Coverage estimation methods for stratified fault-injection," IEEE Transactions on Computers, Volume 48 Issue 7 (1999), pp. 707-723.

[19] E. Czeck, D. Siewiorek "Observations on the effects of fault manifestation as a function of workload," IEEE transactions on Computers, Volume 41 Issue 5 , (1992), pp. 559-566.

[20] M. Dalpasso, M. Favalli, P. Olivo, B. Ricco, "Fault simulation of parametric bridging faults in CMOS IC's," IEEE Transactions on Computer-Aided Design of Integrated Circuits and Systems, Volume 12 Issue 9 (1993). pp. 1403-1410.

[21] T. Delong, B. Johnson, J. Profeta, "A fault injection technique for VDL behavioral-level models," IEEE Design \& Test of Computers, Volume 13 Issue 4 (1996), pp. 24-33.

[22] K. Goswami, "DEPEND: a simulation-based environment for system level dependability analysis," IEEE Transactions on Computers, Volume 46 Issue 1 (1997), pp. 60-74.

[23] J. Hlavicka, S. Racek, P. Herout, "Evaluation of process controller fault tolerance using simulation," Simulation Practice and Theory, volume 7 Issue 8 (2000), pp. 769-790. 
[24] G.-H. Hwang, W.-Z. Shen, "Fault analysis and automatic test patttern for break faults in programmable logic arrays," IEE ProceedingCircuits Devices and Systems, Volume 143 Issue 3 (1996), pp. 157-166.

[25] S.-A. Hwang, J.-H. Hong, C.-W Wu, "Sequential circuit fault simulation using logic emulation," IEEE Transactions on Computer-Aided Design of Integrated Circuits and Systems, Volume 17 Issue 8 (1998). Pp. 724-736.

[26] Hyung Ki Lee, Dong Sam Ha, "HOPE: an efficient parallel fault simulator for synchronous sequential circuits," IEEE Transactions on Computer-Aided Design of Integrated Circuits and Systems, Volume 15 Issue 9 (1996), pp. 1048-1058.

[27] Z. Kaibarczyk, R. Iyer, G. Ries, J. Patel, M. Lee, Y. Xiao. "Hierarchical simulation approach to accurate fault modeling for system dependability," IEEE Transactions on Software Engineering, Volume 25 Issue 5 (1999), pp. 619-632.

[28] W. Kao, r. Iyer, D. Tang, "FINE: A fault injection and monitoring environment for tracing the UNIX system behavior under faults," IEEE Transactions on Software Engineering, Volume 19 Issue 11 (1993), pp. 1105-1118.

[29] J. Karlsson, P. Liden, P. Dahlgren, R. Johanson, U. Gunneflo, "Using heavy ion radiation to validate fault-handling mechanisms," IEEE Micro, Volume 14 Issue 1 (1994), pp. 8-23.

[30] H. Kerkhoff, H. Speck, "Defect-oriented testing of Josephson logic circuits and systems," Physica C: Superconductivity, Volume 350 Issues 3-4 (2001), pp. 261-268.

[31] Kwang-Ting Cheng "Transition fault testing for sequential circuits," IEEE Transactions on Computer-Aided Design of Integrated Circuits and Systems, Volume 12 Issue 12 (1993), pp. 1971-1983.

[32] C. Labovitz, A. Ahuja, A. Bose, F. Jahanian, "Delayed Intrnet routing convergence," IEEE/ACM Transactions on Networking, Volume 9 Issue 3 (2001), pp. 293-306.

[33] R. Lettner, M. Prammer, C. Scherrer, A. Steininger, "Assessment of computer fault toleranceóa fault injection toolset and the rationale behind it," Computer Standards \& Interfaces, Volume 21 Issue 4 (1999), pp. 357-369.
[34] M. Hsueh, T. Tsai, R. Iyer, "Fault injection techniques and tools," Computer, Volume 30 Issue 4 (1997), pp. 75-82.

[35] M. Meyer, R. Camposano, "Active timing multilevel fault simulator with switch-level accuracy," IEEE Transactions on Computer-aided Design of Integrated Circuits and Systems, volume 14 Issue 10 (1995), pp. 1241-1256.

[36] G. Miremadi, J. Torin, "Evaluating processorbehavior and three error-detection mechanisms using physical fault-injection," IEEE Transactions on Reliability, Volume 44 Issue 3 (1995), pp. 441-454.

[37] D. Powell, E. Martins, J. Ariat, Y. Crouzet, "Estimators for fault tolerance coverage evaluation," IEEE Transactions on Computers, Volume 44 Issue 2 (1995), pp. 261-274.

[38] J. Rajski, J. Tyzer, "The analysis of digital integrators," IEEE Transactions on Computers, Volume 42 Issue 6 (1992), pp. 643-650.

[39] J. Rajski, J. Tyzer, "Accumulator-based compaction of test responses," IEEE Transactions on Circuits and Systems II, Volume 39 Issue 5 (1992), pp. 293301.

[40] J. Rajski, J. Tyzer, "Test responses compaction in accumulators with rotate carry adders," IEEE Transactions on Computer-Aided Design of Integrated Circuits and Systems, Volume 12 Issue 4 (1993), pp. 531-539.

[41] H. Seungjae, K. Shin, "Experimental evaluation of behavior-based failure-detection schemes in real-time communication networks," IEEE Transactions on Parallel and Distributed Systems, Volume 10 Issue 8 (1999), pp. 613-625.

[42] G. Silberman, I. Spillinger, "Using functional fault simulation and the difference fault model to estimate implementation fault coverage," IEEE Transactions on Computer-Aided Design of Integrated Circuits and Systems, Volume 9 Issue 12 , (1990). Pp. 13351343.

[43] D. Smith, B. Johnson, N. Andianos, J. Profeta, “A variance reduction technique via fault-expansion for fault-coverage estimation," IEEE Transactions On Reliability, Volume 46 Issue 3 (1997), pp. 366-374.

[44] D. Smith, B. Johnson, J. Profeta, iSystem dependability valuation via a fault list generation algorithm," IEEE Transactions on Computers, Volume 45 Issue 8 (1996), pp. 974-979. 
[45] D. Stort, G. Ries, M. Hsueh, R. Iyer, “Dependability analysis of a high-speed network using softwareimplemented fault injection and simulated fault injection," IEEE Transactions on Computers, Volume 47 Issue 1 (1998), pp. 108-119.

[46] N. Stressman, B. Vinnakota, R. Harjani, "Systemlevel design for test of fully differential analog circuits," IEEE Journal of Solid-State Circuits, Volume 31 Issue 10 (1996), pp. 1526-1534.

[47] C. Stroud, "Reliability of majority voting based VLSI fault-tolerant circuits," IEEE Transactions on Very Large Scale Integration, Volume 2 Issue 4 (1994), pp. 516-521.

[48] A. Tomita, K. Sakamura, "Improving design dependability by exploiting an open model based specification," IEEE Transactions on Computers, volume 48 Issue 1 (1999), pp.24-37.

[49] T. Tsai, M. Hsueh, H. Zhao, Z. Kaibarczyk, R. Iyer, "Stress-based and path-based fault injection," IEEE Transactions on Computers, Volume 48 Issue 11 (1999), pp. 1183-1201.

[50] J. Voas, "Fault injection for the masses," Computer, Volume 30 Issue 12 (1997), pp. 129-130

[51] J. Voas, "Certifying software for high-assurance environments," IEEE Software, Volume 16 Issue 4 (1999), pp. 48-54.

[52] J. Voas, F. Charron, G. McGraw, K. Miller, M. Friedman, "Predicting how badly 'good' software can behave," IEEE Software, Volume 14 Issue 4 (1997), pp. 73-83.

[53] J. Voas, G. McGraw, L. Kassab, L. Voas, “A 'crystal ball' for software liability," Computer, Volume 30 Issue 6 (1997), pp.29-36

[54] C. Walter, "Evaluation and design of an ultra-reliable distributed architecture for fault tolerance," IEEE transactions on Reliability, Volume 39 Issue 4 (1990), pp. 492-499.

[55] C. Yount,, D. Siewiorek, "A methodology for the rapid injection of transient hardware errors," IEEE Transactions on Computers, Volume 45 Issue 8 (1996), pp. 881-891.

[56] M. Zwolinski, "A technique for transparent fault injection and simulation in VHDL," Microelectronics Reliability, Volume 41 Issue 6 (2001), pp. 797-804.

[57] A. White, "Reliability with imperfect diagnostics," Journal Microelectronics and Reliability, Volume 24 Issue 6 (1984), pp. 1069-1076.
[58] S. Wilks, Mathematical Statistics, Wiley, New York, 1963.

[59] S. Karlin and H. Taylor, A First Course in Stochastic Processes, Academic Press, New York, 1975.

[60] Jean-Claude Laprie, "Dependable computing and fault tolerance: concepts and terminology," Proceedings of FTCS-15, 1985, pp.2-11.

[61] A. Friedman, Foundations of Modern Analysis, Dover, New York, 1982.

\section{BIOGRAPHY}

Allan L. White is a research mathematician at NASA Langley. His interests and publications include probability models, design of experiments, and stochastic control. 